\title{
Demarketing Teen Tobacco and Alcohol Use: Negative Peer Influence and Longitudinal Roles of Parenting and Self-Esteem
}

\begin{abstract}
Tobacco and alcohol companies face increasing pressure to prevent smoking and drinking among underage consumers, reinforcing public policy initiatives designed to reduce youth substance use. One approach targets parents to influence their child's behavior. However, the extant literature remains unclear about whether childhood parenting strategies affect children's behavior beyond early adolescence. To fill this void, this research develops an integrative model of parental influence, specifying parenting strategies as antecedents, selfesteem as mediator, and susceptibility to negative peer influence (SPI) and substance use (smoking, and drinking) as socialization outcomes. The findings indicate that childhood parenting strategies impact smoking and drinking in the late teens, by reducing susceptibility to negative peer influence, with self-esteem playing a critical mediating role. These findings not only offer guidelines to social marketers and public policy makers, but also provide new avenues for tobacco and alcohol marketers to be responsive to recent federal laws and regulations, and enhance their corporate social responsibility.
\end{abstract}

Keywords: demarketing, parenting strategies, susceptibility to negative peer influence, selfesteem, smoking, and drinking 


\section{Introduction}

Tobacco and alcohol marketers are under pressure to discourage youthful consumption of their products. This pressure is due in part to the 1998 Master Tobacco Settlement with the National Association of Attorney Generals, and to recent federal laws emphasizing reducing youthful smoking (United States Congress, 2009), and drinking (U.S. Department of Health and Human Services, 2006). Major federal and state government and non-profit initiatives force tobacco and alcohol companies to employ social marketing tactics designed to reduce under-age product consumption. Tobacco and alcohol marketers must become proactive and effective in their efforts to reduce product use among children and adolescents. These concerns are migrating to fast food companies addressing concerns about growing child obesity. Until recently, reactive policy enforcement monitored and disciplined tobacco and alcohol marketers targeting youth. Companies must abandon traditional advertising campaigns targeting children and teens; the new theme aims to reduce negative peer influence. Only recently, tobacco companies (e.g., Phillip Morris), non-profit organizations (e.g., Tobacco Free Kids), and alcohol (e.g., PSA Central) and smoking (e.g., Centers for Disease Control) public policy organizations started targeting parents recommending strategies to accomplish these goals.

Negative peer influence affects addictive consumption and maladaptive social behaviors tied to corporate advertising and promotion, including smoking (Pechmann and Knight, 2002), drinking (Duncan, Duncan, and Strycker, 2006), and drinking and driving (Hartos, Eitel, and Simons-Morton, 2002). This linkage leads social marketers to launch ad campaigns, and develop community and school interventions targeting children and teens to resist negative peer influence for both smoking (Pechmann and Knight, 2002) and drinking (Rose, Bearden, and Teel, 2001). Tobacco and alcohol marketers as well as social marketers need to understand and eliminate the 
causes of child and teen susceptibility to negative peer influence (SPI), and their effect on teen smoking and drinking. To date, little consumer research investigates why some children are more susceptible to peer-pressure on consumption-related misbehaviors than others (John, 1999).

This paper proposes that parenting strategies can at least partially explain such individual differences in SPI among youth. Parents are important socialization agents in a young child's developmental process (Moschis, 1987). Acknowledging parenting's role as a critical shaping force on child socialization, marketing researchers associate parenting strategies with several children's consumption-related (mis)behaviors. For example, researchers link parental responsiveness to children's use of influence strategies in family purchases (Bao, Fern, and Sheng, 2007), credit card abuse (Palmer, Pinto, and Parente, 2001), and sexual knowledge, attitudes, and behavior (Moore, Raymond, Mittelstaedt, and Tanner, 2002). Recently, some scholars also link parental responsiveness and psychological control to child smoking initiation and growth (Simons-Morton, 2002; Yang and Schaninger, 2010a), and drinking (Bogenschneider and Pallock, 2008). In line with these findings, marketers develop parent-oriented marketing campaigns to complement the conventional child-targeted intervention programs. Tobacco Free Kids, for example, uses advertisements to educate parents to be more responsive to their children as a preventive approach to curtail child smoking.

Three problems exist in the literature. First, the findings are primarily from younger children, but evidence is lacking to determine whether or not parenting strategies significantly impact teen consumption-related behaviors as they grow up. Although some researchers find parental influence remains important after children become teenagers (Shim, 1996; Yang and Schaninger, 2010a, 2010b), others suggest that its impact declines and peer influence takes precedence during adolescence (Youniss and Smollar, 1985). Second, researchers know little 
about the key mechanism underlying how parenting influences SPI or maladaptive consumption. This paper proposes that self-esteem is a core driver. Parenting strategies exert a prolonged impact on children's behavior as they grow up. Previous research suggests that self-esteem plays an important role in determining children's psychological development (Kaplan, 1982) and consumption-related attitudes and behaviors (Bearden, Netemeyer, and Teel, 1989). If the present research supports this proposition, the results offer new avenues for social marketers to combat teen substance use. Identifying the parenting strategies that offers sustained inoculation against peer pressure and substance use benefits many stakeholders. Finally, most studies relating parenting strategies to consumer misbehavior (e.g., Bogenschneider et al. 1998; Bogenschneider and Pallock, 2008; Moore et al., 2002) focus only on one of the three parenting strategies (usually parental responsiveness). Little is known about each parenting strategy’s relative importance.

To address these issues, the paper develops and tests a conceptual model of SPI and substance use, specifying all three parenting strategies (i.e., parental responsiveness, psychological control, and behavioral control) as antecedents, and self-esteem as mediator. Two inter-related studies test the proposed model. The first study is a cross-sectional study of 14-15 year old teens, the age at which peer influence becomes more important than parental influence; thus providing a conservative test of the model. The second study is a longitudinal study of the impact of parenting strategies when the children are at ages of 10-11, on subsequent self-esteem, SPI, and smoking and alcohol use six years later, when they are 16-17 year old teens.

This paper makes three incremental contributions. First, the research examines the extended (temporal) long-lasting impact of childhood parenting strategies on subsequent SPI and substance use in the late teens. Second, the study incorporates self-esteem as the mechanism by 
which parenting strategies affect teen SPI and substance use. Third, the methodology simultaneously examines the effect of all three parenting strategies on teen SPI and substance use, providing a clearer picture of the distinct effect of one particular parenting strategy in the presence of others.

\section{Theoretical Development}

Consumer socialization theory (Moschis, 1987) and parenting theory (Barber, 1997) provide the foundation for this paper's research framework. One important aspect of consumer socialization is parenting strategies, including responsiveness, psychological control, and behavioral control (Barber, 1997). Parental responsiveness is the extent to which parents express interest in children's activities, supportive of children's requests, and engage in positive parentchild interactions. Psychological control is the extent to which parents use manipulative and punitive behaviors during the child-rearing process. Behavioral control is the degree to which parents monitor their child's activities and friends, and set clear rules, and dispense consistent discipline (Barber, 1996). This paper proposes an integrative model (see Figure 1), specifying parenting strategies as antecedents, self-esteem as mediator, and SPI and substance use as consequences.

Figure 1 here.

\subsection{Effect of Parenting Strategies on SPI and Substance Use}

Figure 1's model specifies that parental responsiveness reduces both SPI and substance use. Parental responsiveness leads to better parent-child relationships and more open communication between them (Peterson and Hann, 1999), reducing the likelihood of children's substance use or association with delinquent peers (Kandel, 1996). Using data from mothers, Bogenschneider and associates find that parental responsiveness enhances children's orientation 
toward parents, rather than peers, for advice on personal issues, which in turn, impedes child smoking (Bogenschneider et al., 1998) and drinking (Bogenschneider and Pallock, 2008).

$\mathbf{H}_{1}$ : Parental responsiveness negatively relates to children's $(a)$ SPI, $(b)$ smoking, and (c) drinking.

In contrast, psychological control likely shows a reverse pattern, leading to increased SPI and substance use. Psychologically controlling parenting leads to strong expectations of conformity/obedience, and excessive, arbitrary, and coercive parental behaviors (Barber, 1996). Psychological control often produces youthful addictive consumption as a rebellious reaction against parents (Kandel, 1996), and increases association with deviant peers as an act of rebelling against manipulative control (Fuligni and Eccles, 1993). Manipulative parenting develops impulsivity, aggression, delinquency, drug use, and sexual precocity among youth (Barber, 1996).

$\mathbf{H}_{2}$ : Parental psychological control positively relates to children's (a) SPI, (b) smoking, and (c) drinking.

Behavioral control closely aligns with what Stattin and Kerr (2000) call 'parental monitoring,' although the former is broader in scope than the latter and includes rule making and consistent discipline. Evidence linking behavioral control to SPI is mixed. Most studies examining behavioral control's effect on SPI focus on younger children. Bogenschneider et al. (1998) find that parental monitoring per se does not reduce negative peer influence among midteens, but that restraining their relations with peers does. However, they cite studies that find parental monitoring is effective for younger children. Other studies conclude that behavioral control reduces association with substance using peers. For example, Dishion and Loeber (1985) find illegal drug usage positively relates to affiliation with deviant peers and negatively relates to 
parental behavioral control (but alcohol use does not), implying that behavioral control negatively links to SPI, and thus, drug abuse. Bogenschneider et al. (1998) view behavioral control as less important than responsiveness in predicting children's behavior after they enter adolescence. Adolescents strive to remain connected to parents while simultaneously seeking autonomy. For adolescents, the transformation of the parent-adolescent relationship rather than behavioral control, affects the relative influence of peers.

Stattin and Kerr (2000) contend that the negative link in earlier studies between parental monitoring and delinquent norm breaking is due to measures of 'monitoring' capturing voluntary child disclosure of friends and activities rather than parental surveillance. They argue that parental responsiveness drives voluntary disclosure. Fletcher, Steinberg, and Williams-Wheeler (2004), however, disagree, and suggest that their 'disentangled' parental monitoring measures both indirectly (via peers) and directly impact teen problem behaviors. Further confounding the issue, behavioral control tends to reduce negative peer influence and association with peers who use alcohol, tobacco, and drugs, when accompanied by high parental involvement (a component of responsiveness) (Jackson et al., 1997). The above discussion leads to two alternative hypotheses:

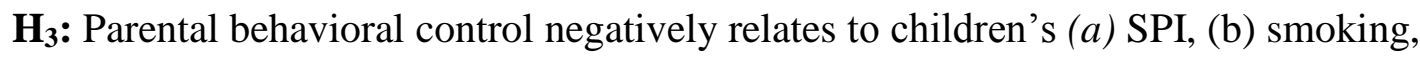
and $(c)$ drinking.

$\mathbf{H}_{3 \text { alt }}$ : Parental behavioral control positively relates to children's (a) SPI, (b) smoking, and (c) drinking.

\subsection{Effect of SPI on Substance Use}

The model posits a positive link between SPI and substance use (smoking and drinking). Negative peer influence induces deviant behaviors by role modeling (Kandel, 1996), and by 
shaping norms favorable to substance use (Ennett and Bauman, 1991). In many cases, adolescents perceive substance use as "functional," helping to fulfill their developmental needs. Substance use becomes a threshold to sensing peer group acceptance and belonging as well as identity formation. Teens often report that they smoke or drink to be sociable or part of the group (Pavis, Cunningham-Burley, and Amos, 1997). Previous research also shows that reliance on peers, rather than parents, to resolve personal problems positively relates to smoking (Bogenschneider et al., 1998) and drinking (Bogenschneider and Pallock, 2008).

$\mathbf{H}_{4}$ : Children's SPI positively relates to $(a)$ smoking and $(b)$ drinking.

\subsection{Mediating Role of Self-esteem on the Effect of Parenting on SPI and Substance Use}

The research model also proposes that the core mechanism underlying the effect of parenting strategies on SPI and substance use is the child's self-esteem. A central theme among self-concept theories is social experiences influence an individual's self-evaluation. Through extended interactions with their parents from an early age, children internalize parents' expectations, slowly building a self-evaluation. During this process, supportive social experiences (e.g., responsive parenting) effectively convey information to young people about their self-worth and instill a sense of their inherent value-increasing self-esteem (Openshaw, Thomas, and Rollins, 1984). Previous studies support the notion that parental affection or support increases child self-esteem; failure to receive parental approval during parent-child interactions decreases self-worth (Hoelter and Harper, 1987).

H5: $_{5}$ Parental responsiveness positively relates to children's self-esteem.

Parental psychological control represents a high level of expectation of child conformity and obedience and the use of excessive, arbitrary, and coercive parental behaviors to reach this goal (Barber, 1997). Such arbitrary controlling attempts fail to communicate clear expectations 
and do not provide children a benchmark to evaluate themselves. Communicating rejection and a lack of respect to children often devalues the sense of self and creates poorer self-evaluations. Congruent with this logic, past research shows that psychological control undermines children's self-esteem, while granting autonomy encourages the opposite (Allen and Hauser, 1994).

$\mathbf{H}_{6}$ : Parental psychological control negatively relates to children's self-esteem.

The literature is inconclusive regarding behavioral control's effect on self-esteem. Jackson et al. (1997) develop a multiple-item, behaviorally based parenting effectiveness scale (as rated by the child) combining responsiveness and behavioral control. The authors find a positive relationship between child self-esteem and resistance to negative peer influence. However, the effect of behavioral control does not differ from that of responsiveness, and only grade-school children are studied. Steinberg et al. (1994) find that an effective amount of behavioral control enhances child confidence and self-esteem, but overuse can backfire. Furthermore, Kerr, Stattin, and Biesecker (2003) argue that while a superficial positive association exists between behavioral control and self-esteem, trust and attachment, rather than monitoring and discipline, may be the true drivers of this link. The discrepancies mentioned above suggest the following competing hypotheses:

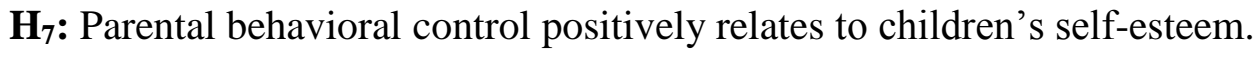

$\mathbf{H}_{\text {7alt }}$ : Parental behavioral control negatively relates to children's self-esteem.

Low self-esteem individuals report more loneliness than their high self-esteem counterparts, experience higher social anxiety levels, and describe themselves as having fewer friends (Baumeister and Leary, 1995). They strive to gain the approval of others, leading to selfpresentation strategies, such as voicing agreement with the views of significant others (Premeaux and Bedeian, 2003). Similar findings appear in consumption-related contexts. Prior research 
shows self-esteem negatively relates to normative interpersonal influence on purchasing decisions, and social comparison in consumption-related issues (Bearden, Netemeyer, and Teel, 1989). Conversely, higher self-esteem levels reduce children's tobacco and alcohol use (Yang and Schaninger, 2010a, 2010b).

H8: Children's self-esteem negatively relates to their (a) SPI, (b) smoking, and (c) drinking.

Extending this discussion, self-esteem likely mediates parenting strategies' impact on the socialization outcomes. Adding self-esteem to the parenting-outcome linkages, the parenting strategies' direct impact on SPI, smoking, and drinking declines or becomes nonsignificant. On the other hand, the indirect path from parenting to children controlling for selfesteem will be significant. Although $\mathbf{H}_{5}$ through $\mathbf{H}_{\mathbf{8}}$ depict all the links related to the mediating role of self-esteem, the paper separately develops $\mathbf{H}_{\mathbf{9}}$ to test mediation formally.

$\mathbf{H}_{9}$ : Children's self-esteem mediates the parenting strategies' impact on SPI, smoking, and drinking.

Assuming the results support $\mathbf{H}_{\mathbf{9}}$, and self-esteem is the key mechanism, parenting strategies would have a time-lag effect on subsequent SPI and substance use. In other words, effective parenting should have a carryover effect on negative peer influence and consumption-related misbehaviors through a prolonged effect on the child self-esteem. Although the literature offers little direct evidence to support this expectation, the following findings provide indirect support for the proposed time-lag effect: Parenting strategies, especially responsiveness and psychological control, exert a great influence on children's selfesteem across different age groups. Parental responsiveness provides a fertile soil to nourish confidence and self-worth of toddlers (Skinner 1998). Responsive parenting also increases 
self-reported self-esteem among $4^{\text {th }}$ and $5^{\text {th }}$ graders (Openshaw, Thomas, and Rollins, 1984), and college students $\left(M_{\mathrm{age}}=20.8\right)$ (Parish and McCluskey 1993). Although these findings are from different people and age groups, similar effects likely exist within an individual over time, that is, parenting strategies at an earlier time likely affect the same person's self-esteem at later developmental stages.

$\mathbf{H}_{\mathbf{1 0}}$ : Parenting strategies in childhood have a long-lasting, 'lagged,' or carryover effect on subsequent SPI and substance use through self-esteem.

\section{Method}

Two studies, based on different portions of a nationally representative longitudinal panel of children and youth over a six-year time span, test these hypotheses. Study 1 is cross-sectional, based on mid-teens (ages 14-15), and examines the relationships among parenting strategies, self-esteem, SPI and substance use (smoking and drinking). Sampling mid-teens to test the model is useful for two reasons. First, such data likely provide conservative tests of the hypotheses. Previous research suggests parents tend to lose their influence over their children at this age (Youniss and Smollar, 1985), and that parental behavioral control becomes less effective as peer influence increases (Bogenschneider et al., 1998). Second, few studies examine midteenagers (most focus on childhood). Mid-adolescence is an important age cohort needing greater attention on how parenting facilitates or hinders their development of smoking and drinking habits.

Study 2 presents a longitudinal model examining parenting strategies' impact during late childhood (ages 10-11) on subsequent long-term self-esteem, SPI, and substance use, when those youths are late teenagers aged 16-17. No known previous studies examines such a long-term, lagged effect of late childhood parenting on late teen self-esteem, SPI, and smoking and drinking 
frequencies.

\subsection{Sample and Procedures}

The sample for Study 1 is from Cycle 3, whereas the sample for Study 2 is from Cycles 1 and 4 of the National Longitudinal Survey of Children and Youth (NLSCY), a nationwide representative sample gathered by Statistics Canada to understand the growth and psychological development of Canadian children and youth. The NLSCY began in 1994-95, with 15,579 households with children aged between 0 and 11, followed at two-year intervals. Of the households assessed in 1994-95, 3,434 families had at least one 10 or 11-year old child, who completed a questionnaire at ages 10-11 (Cycle 1). The same sample fell to 2,249 in Cycle 2 (1996-7; ages 12-13), 1,817 in Cycle 3 (1998-9; ages 14-15), and 1,414 in Cycle 4 (2000-01; ages 16-17). A series of MANOVA analyses showed that respondents and non-respondents in both Cycles 2 and 3 did not differ significantly in the three parenting strategies measured in Cycle 1. Therefore, differential mortality is not an issue for model testing.

\subsection{Measures}

Independent and mediating variables. The NLSCY assessed parental responsiveness, behavioral control, and psychological control using Lempers, Clark-Lempers, and Simons' (1989) Parental Behavior Inventory (1=never; 5=very often). In measuring parental responsiveness ( $\alpha=.77$ in both Cycles 1 and 3), the NLSCY asks the children to rate how often their parents smiled at them, praised them, made sure that they knew they were appreciated, spoke of the good things they did, and seemed proud of the things they did. To assess psychological control ( $\alpha=.65$ in Cycle 1 and .69 in Cycle 3), the NLSCY asked the children to rate how often their parents: soon forgot a rule they had made; nagged them about little things; only kept rules when they suited them; threatened punishment more often than they used it; 
enforced or not enforced a rule depending on their mood; and hit them or threatened to do so. Similarly, the NLSCY gauged behavioral control ( $\alpha=.55$ in Cycle $1, .65$ in Cycle 3$)$ by asking the children to rate how often their parents: wanted to know exactly where they were and what they were doing; told them what time to be home when they went out; told them what they could watch on TV; made sure they did their homework; and found out about their misbehaviors.

The NLSCY gauged child/teen self-esteem, the proposed mediating mechanism in this paper, using four items ( $\alpha=.72$ in Cycle 3 and .71 in Cycle 4) from the Marsh's (1988) GeneralSelf Scale. The respondents self-report if they liked the way they are, whether they have a lot to be proud of, whether lots of things about them are good, and if they do things well.

Dependent variables. The NLSCY measures SPI with Bogenschneider et al.’s (1998) two-item Relative Peer Orientation scale, asking respondents to indicate whether or not they have anyone else (other than their close friends) to talk to about themselves or their problems. If the answer was "yes," they answered a second question in which they chose from a list of 14 people they would like to talk to, four of whom were parents or caregiver adults. Following Bogenschneider et al. (1998), the authors derived SPI such that: Those respondents who chose to talk only to friends but not to parents or caregivers were high peer-oriented (1), while those who chose to talk to both friends and a parent/caregiver were low peer-oriented (0). This categorization is often employed to indicate susceptibility to negative peer influence, and linked to a variety of misbehaviors, including smoking, drinking, and drug use (see Bogenschneider and Pallock 2008, for a review).

Study 1 uses child/teen-reported alcohol and smoking frequencies from Cycle 3 (ages 1415), with $0=\mathrm{I}$ don't smoke/drink anymore; $1=\mathrm{a}$ few times a year; $2=$ about once or twice a month; $3=$ about once or twice a week; $4=$ about 3 to 5 times a week; and 5=every day. Study 2 uses the 
same measures at Cycle 4 (ages 16-17).

Statistics Canada provides weighted means of the three parenting strategies and selfesteem for testing causal models. They use a working weight (a child's weight divided by the mean of the weights across the sample) to derive these composite scores. To ensure the data represent the Canadian population at the time of sample selection, the NLSCY adjusts nonresponses using each child's weight, and post-stratifies according to province, age, and gender.

\section{Analyses and Results}

Path analysis through the MPlus software tested the hypotheses. Unlike the conventional programs such as LISREL, EQS or AMOS, the MPlus software can handle categorical dependent variables and accurately computes the standard errors (Muthén and Muthén 2007). Following recommendations from Statistics Canada, the authors used composite indices, rather than latent factors, of the three parenting strategies and self-esteem in both studies. As indicated earlier, the first study (Figure 2) tested the conceptual model using Cycle 3 data only (mid-teens aged 14-15), and the second study (Figure 3) examined the impact of early parenting in Cycle 1 (ages 10-11) on these intermediate and dependent variables in Cycle 4 (ages 16-17). Both models in Figures 2 and 3 show evidence of excellent data fit (Figure $2: \chi^{2}=1.4, \mathrm{df}=1, \chi^{2} / \mathrm{df}=1.4, p=.24$, $\mathrm{CFI}=1.00, \mathrm{RMSEA}=.000$; Figure $3: \chi^{2}=0.91, \mathrm{df}=1, \chi^{2} / \mathrm{df}=0.91, p=.34, \mathrm{CFI}=1.00, \mathrm{RMSEA}=.000$ ). A plausible reason for a smaller $\chi^{2}$ is these models used weighted composite scores (rather than latent factors). Since measurement errors are not incorporated, the path analysis results are similar to the correlation matrix.

Figure 2 here.

Figure 3 here.

\subsection{Study 1}


Since Study 1 uses cross-sectional data, the following two approaches evaluate the potential threat of common methods bias. First, the correlation matrix identifies highly correlated factors. Common method bias likely exists when extremely high correlations occur $(r>0.90)$ (Pavlou, Liang, and Xue, 2007). Since correlation results are low (ranging from .01 to .41), common method bias is unlikely. Second, following Podsakoff et al. (2003), a theoretically unrelated variable (aka "marker") is incorporated into the model. If common method bias exists in the data, the marker variable would relate significantly to other model constructs. In the analysis, the measure of "if I need extra help, my teacher gives it to me" (1=never; $5=$ all the time $)$ serves as the marker variable. Structural parameters are examined by comparing the model containing the marker variable to the other one that does not. The results show that the marker variable is not significantly related to any of the model constructs ( $p>.15)$. Adding the marker variable does not alter any of the path coefficients' sign, magnitude, or significance levels, either. Including the marker variable as a control variable results in a non-significant change in $\chi^{2}$ $\left(\Delta \chi^{2}=2.9, \Delta \mathrm{df}=3, p>.40\right)$. These results suggest the data do not suffer from common method bias.

$\mathbf{H}_{\mathbf{1}}$ specifies that parental responsiveness negatively relates to (a) SPI, (b) smoking, and (c) drinking. Supporting $\mathbf{H}_{\mathbf{1}}$, responsiveness negatively affects SPI ( $\left.b=-.303, p<.001\right)$. Although responsiveness's direct effect on smoking or drinking is not statistically significant, the results show a negative effects on smoking indirectly through both SPI (SPI $\rightarrow$ smoking: $b=.101, p<.01$ ) and self-esteem (responsiveness $\rightarrow$ self-esteem: $b=.351, p<.001$; self-esteem $\rightarrow$ smoking: $b=-$ $.109, p<.001)$. Similarly, parental responsiveness also negatively affects drinking frequency indirectly through SPI (SPI $\rightarrow$ drinking: $b=.194, p<.001$ ) and self-esteem (self-esteem $\rightarrow$ drinking: $b=-.067, p<.05)$. These results partially support $\mathbf{H}_{\mathbf{1 b}}$ and $\mathbf{H}_{\mathbf{1 c}} \cdot \mathbf{H}_{\mathbf{2}}$ proposes psychological control positively affects (a) SPI, (b) smoking, and (c) drinking. As proposed by 
$\mathbf{H}_{2 \mathrm{a}}$, psychological control positively associates with SPI $(b=.152, p<.001)$, and affects smoking and drinking indirectly through SPI and self-esteem (psychological control $\rightarrow$ self-esteem: $b=-$ $.108, p<.01$ ), partially supporting $\mathbf{H}_{2 \mathrm{~b}}$ and $\mathbf{H}_{\mathbf{2 c}}$ respectively. $\mathbf{H}_{3}$ proposes behavioral control negatively affects (a) SPI, (b) smoking, and (c) drinking, whereas the competing hypothesis $\mathbf{H}_{\mathbf{3 a l t}}$ predicts a positive link from behavioral control to SPI, smoking, and drinking. The results show behavioral control directly affects SPI $(b=-.136, p<.001)$, and indirectly affects both smoking and drinking through SPI, fully supporting $\mathbf{H}_{\mathbf{3 a}}$ and partially supporting $\mathbf{H}_{\mathbf{3 b}}$ and $\mathbf{H}_{\mathbf{3 c}}$, while the data do not support $\mathbf{H}_{3 \text { alt }} \cdot \mathbf{H}_{\mathbf{4}}$ proposes SPI positively associates with (a) smoking and (b) drinking. $\mathbf{H}_{\mathbf{4}}$ is supported, based on the results reported above.

$\mathbf{H}_{5}$ proposes a positive link from parental responsiveness to self-esteem. Consistent with $\mathbf{H}_{5}$, responsiveness positively relates to self-esteem $(b=.351, p<.001) . \mathbf{H}_{\mathbf{6}}$ depicts a negative relationship between psychological control and self-esteem. In line with $\mathbf{H}_{\mathbf{6}}$, the link between psychological control and self-esteem is negative and significant $(b=-.108, p<.01) . \mathbf{H}_{7}$ specifies a positive association between behavioral control and self-esteem, whereas the competing hypothesis $\mathbf{H}_{7 \text { alt }}$ predicts a negative association. Neither $\mathbf{H}_{7}$ nor $\mathbf{H}_{7 \text { alt }}$ is supported, since the link between behavioral control and self-esteem does not reach statistical significance. $\mathbf{H}_{\mathbf{8}}$ states selfesteem negatively relates to (a) SPI, (b) smoking, and (c) drinking. Consistent with $\mathbf{H}_{\mathbf{8 a}}, \mathbf{H}_{\mathbf{8 b}}$, and $\mathbf{H}_{\mathbf{8 c}}$, the results reveal negative links from self-esteem to SPI $(b=-.077, p<.05)$, smoking $(b=-.109$, $p<.001)$, and drinking $(b=-.067, p<.05)$, respectively.

$\mathbf{H}_{9}$ predicts the mediating role of child's self-esteem. A series of analyses examined whether self-esteem mediates the relationship between parenting strategies and the socialization outcome variables examined in the paper (i.e., SPI, smoking, and drinking). Three models tested mediation using Baron and Kenny's (1986) procedures: (1) a parenting-outcome model 
examining the direct effects of parenting on SPI, smoking, and drinking; (2) a parenting-esteem model examining the effect of parenting on self-esteem; and (3) a model examining the effect of parenting on both self-esteem and socialization outcome variables. If significant effects in the expected direction are found for models (1) and (2), and the effect of self-esteem on socialization outcome variables is significant in model (3), then evidence of mediation exists.

The results indicate: (1) significant effects for parenting strategies on SPI (responsiveness: $b=-.339, p<.001$; psychological control: $b=.161, p<.001$; behavioral control: $b=-.144, p<.001$ ), smoking (responsiveness: $b=-.078, p<.05$; psychological control: $b=.116$, $p<.001$; behavioral control: $b=-.066, p<.05$ ) and drinking (responsiveness: $b=.008, p>.15$; psychological control: $b=.227, p<.001$; behavioral control: $b=-.091, p<.05$ ); (2) significant effects of parenting strategies on self-esteem (responsiveness: $b=.377, p<.001$; psychological control: $b=-.116, p<.01$; behavioral control; $b=.051, p>.10)$; and (3) significant effects of selfesteem on SPI $(b=-.077, p<.05)$, smoking $(b=-.109, p<.001)$, and drinking $(b=-.067, p<.05)$ in the proposed mediation model. All paths reported are in the hypothesized directions, thereby supporting $\mathbf{H}_{9}$. A follow-up comparison between the direct model and the mediation model shows that when adding self-esteem, the effect of all three parenting strategies on SPI retains significance, whereas none of the links from parenting strategies to smoking or drinking is significant statistically. These results indicate that self-esteem partially mediates the effect of parenting strategies on SPI, but fully mediates the effect of parenting strategies on smoking and drinking (Baron and Kenny 1986).

\subsection{Study 2}

$\mathbf{H}_{10}$ proposes childhood parenting has a lasting impact on subsequent late-teenage selfesteem, SPI, and thus smoking and drinking. As shown in Figure 3, Cycle 1 parental 
responsiveness exerts a direct impact on Cycle 4 self-esteem $(b=.150, p<.001)$ and SPI $(b=-.098$, $p<.01)$, and indirectly affects Cycle 4 smoking and drinking through self-esteem (self-esteem $\rightarrow$ smoking: $b=-.091, p<.01)$ and SPI (SPI $\rightarrow$ smoking: $b=.150, p<.001$; SPI $\rightarrow$ drinking: $b=.171$, $p<.001)$. Similarly, Cycle 1 psychological control directly influences Cycle 4 self-esteem $(b=-$ $.081, p<.01)$ and SPI $(b=.079, p<.05)$, and indirectly influences Cycle 4 smoking and drinking through self-esteem and SPI. These results lend support for $\mathbf{H}_{\mathbf{1 0}}$.

A closer look at the significant paths in Figure 3 also shows the longitudinal model fully supports $\mathbf{H}_{\mathbf{1 a}}$ (direct effect of Cycle 1 responsiveness on Cycle 4 SPI), and partially supports $\mathbf{H}_{\mathbf{1 b}}$ and $\mathbf{H}_{1 \mathbf{c}}$ (indirect effect of Cycle 1 responsiveness on Cycle 4 smoking and drinking through Cycle 4 self-esteem and SPI). Similarly, $\mathbf{H}_{2 \mathbf{a}}$ is supported, but $\mathbf{H}_{2 \mathbf{b}}$ and $\mathbf{H}_{2 \mathbf{c}}$ only are supported partially, as evident by a direct link from Cycle 1 psychological control to Cycle 4 SPI and the indirect links from Cycle 1 psychological control to Cycle 4 smoking and drinking through Cycle 4 self-esteem and SPI. Consistent with $\mathbf{H}_{\mathbf{4 a}}$ and $\mathbf{H}_{\mathbf{4 b}}$, SPI exerts significant impact on both smoking and drinking in Cycle 4. Supporting $\mathbf{H}_{\mathbf{5}}$ and $\mathbf{H}_{\mathbf{6}}$, responsiveness and psychological control in Cycle 1 significantly associate with self-esteem in Cycle 4. Self-esteem significantly affects SPI $(b=-.305, p<.001)$ and smoking $(b=-.091, p<.01)$ in Cycle 4 as well as exerts a negative effect on drinking via SPI. These results support $\mathbf{H}_{\mathbf{8 a}}, \mathbf{H}_{\mathbf{8 b}}$, and $\mathbf{H}_{\mathbf{8 c}}$. The same procedures were followed to test self-esteem's mediating role for the time-lag effect. The results show that Cycle 4 self-esteem partially mediates the effect of Cycle 1 parental responsiveness and psychological control on Cycle 4 SPI, and fully mediates the effect of Cycle 1 responsiveness and psychological control on Cycle 4 smoking. These results support $\mathbf{H}_{9}$. The summary of hypothesis testing results is presented in Table 1.

Table 1 here. 


\section{General Discussion}

Researchers argue that parenting strategies do not exert much impact on children's consumption-related socialization outcomes after they enter adolescence, because they strive for independence and seem more susceptible to peer influence than to parental influence. Extending previous research, the present study shows parenting strategies $\boldsymbol{d o}$ affect teenagers' susceptibility to negative peer influence and substance use (smoking and drinking). Such effects are long lasting (over a course of six years in the study), rather than temporary. The core mechanism underlying the effect of parenting strategies is the child's self-esteem. Both cross-sectional and longitudinal data from a nation-wide representative sample support the proposed parental effects and the self-esteem mechanism.

The findings suggest responsive parenting reduces smoking and drinking by strengthening the child self-esteem. In addition, responsive parenting reduces adolescents' reliance on peers in both the short-term and the long run. Increasing parental responsiveness leads teens to rely less on their peers for consumption standards. High, long-term self-esteem and extended autonomy from group social pressure also may ensue. The reverse holds for psychological control. Psychologically controlling parenting increases negative peer influence both directly, and indirectly, through negative impact on self-esteem. The stronger direct impact for teens is consistent with the view that overly controlling parenting is antithetical to individualism and autonomy, and thus alienates teens from their parents and leads them to exhibit rebellious behavior and rely on friends rather than parents for normative guidance to defend the adolescent's self-esteem.

\subsection{Theoretical Contributions}

From a conceptual perspective, this research extends both parenting theory and the 
traditional consumer socialization framework. Prior research mainly focuses on parental responsiveness in studying children's socialization outcomes. Extending previous research, this study proposes and empirically tests three parenting strategies simultaneously in the same framework. The results advance the understanding about the distinct effect of each parenting strategy controlling for the other strategies' effects. The findings provide valuable insights to help explain the previously mixed findings regarding the role of behavioral control.

In addition, this study extends the consumer socialization framework by incorporating self-esteem as the key mechanism underlying the socializing role of parenting strategies. The prevalence of other socialization agents, such as cell phone 'texting,' and the Internet, particularly Facebook, likely further diminishes parental influence. Despite the important role that other socialization agents play in children's lives, the current research proposes and verifies that parents remain a critically important socializer affecting their offspring's tobacco and alcohol use, both short- and long-run. Parenting strategies can mitigate the negative impact of SPI, in an enduring fashion through the child's self-esteem. These insights are important to the extant literature, and represent unique and important incremental contributions.

\subsection{Managerial Contributions}

Thus far, targeting parents has not been viewed as an important demarketing tool, despite its recent emphasis by social marketers, and inclusion in tobacco and beer/alcohol marketer's websites in response to increasing legal and federal policy regulations. The present study's findings provide strong evidence that marketers should add parent-oriented marketing campaigns to the existing 'toolkits' and integrate them with conventional adolescent communication and intervention programs to reduce susceptibility to negative peer influence and substance use.

Some Heritage Foundation website links imply that "Big Tobacco" purposely designs 
teen-targeted anti-smoking ads to have a subtle influence in a direction contrary to that implied. Wakefield et al. (2006) charge that exposure of teens to industry sponsored anti-smoking campaigns targeting parents actually increases approval of smoking and tobacco usage over the past 30 days among teens exposed to those ads. That conclusion implies boomerang effects. Based on this study, the authors suggest tobacco and alcohol manufacturers should center on parenting themes in their parent-oriented marketing campaigns. The parent-oriented ads need not teach parents how to control their children's tobacco and/or alcohol use. The focus should be on teaching parents to avoid using psychological control and increase parental responsiveness. Such parent-targeted campaigns can be effective in combating teen smoking and drinking, while minimizing possible boomerang effects.

The findings also suggest existing (anti teen-smoking and drinking) campaigns err by targeting parents of teenagers, when they should be reaching parents of children in mid- to latechildhood. Late childhood parenting's impact on subsequent self-esteem, negative peer orientation, and drinking and smoking is striking. Tobacco and alcohol marketers, as well as social marketers, also should target late grade-school children with self-esteem themes, and try to immunize them against negative peer influence. Existing approaches underemphasize the importance of combining responsiveness and behavioral control-during mid-adolescence. Parents must be cautioned against overuse of behavioral control in the absence of a warm positive relationship with their child, and warned that psychological control can backfire and increase children's vulnerability to negative peer influence, especially in their mid-teens when they strive for independence. Because adolescents become more peer-oriented and less parentoriented, the importance of establishing 'the inoculation' effect of positive parenting early is paramount. Research should determine whether or not to target parents of teenagers, with fear 
appeals of the negative effect of psychological control, or of decreasing responsiveness and increasing psychological control. Child-targeted themes combining self-esteem and social norms must be examined as well.

Coordinated campaigns could utilize spot TV to reach neighborhoods with "at risk" demographic profiles, and those associated with heavier drinking, smoking, and other risky behaviors. Special attention must be given to the areas with high concentrations of single parent and blended families, low social economic status, neighborhood violence, deviant peers, and atrisk cultural backgrounds. Such an approach differentially targets parents of teens most vulnerable to negative peer pressure, and reaches neighborhoods with low responsiveness parents but they exhibit high psychological control.

\subsection{Limitations and Future Research Directions}

Like any study, this research is characterized by a number of limitations. First, all measures are self-reported without actual behavioral data. Although common method bias unlikely threatens the finding's internal validity, future research should collect behavioral measures offering an opportunity to test the framework more rigorously. Second, the Cronbach alpha values for psychological control and behavioral control measures are below the recommended threshold of 0.70 . Marketers should be cautious in interpreting the findings related to these two constructs. Third, the model only examines smoking and drinking. Future research may expand the types of maladaptive behaviors examined to include others of important societal and individual longer-term health interest, including illegal drug use, drinking and driving, risky sexual behaviors, body modifications (e.g., piercing and tattoos), and binge eating. Finally, a useful study extension is examining the interactive effects of marketing activities, parenting strategies, and negative peer influence. Such findings likely will provide marketing practitioners 
useful guidelines on how to improve their parent-targeted communication campaigns so families can change their parenting strategies to bring about reduced susceptibility to negative peer influence and maladaptive behaviors among the youth.

\section{REFERENCES}

Allen JP, Hauser ST. Longitudinal Assessment of Autonomy and Relatedness in Adolescentfamily Interactions as Predictors of Adolescents' Ego Development and Self-Esteem, Child Development 1994;65:179-194.

Bao Y, Fern EF, Sheng S. Parental Style and Adolescent Influence in Family Consumption Decisions: An Integrative Approach. J Business Research 2007; 60:672-680.

Barber BK. Parental psychological control: Revisiting a neglected construct. Child Development 1996; 67:3296-3319.

Barber BK. Introduction: Adolescent socialization in context - the role of connection, regulation, and autonomy in the family. J Adolescent Res 1997;12:5-11.

Baron RM, Kenny DA., The Moderator-Mediator Variable Distinction in Social Psychological Research: Conceptual, Strategic and Statistical Considerations, J Personality Soc Psychol 1986; 51:1173-1182.

Baumeister RF, Leary MR. The Need to Belong: Desire for Interpersonal Attachments as a Fundamental Human Motivation, Psychological Bulletin 1995;117:497-529.

Bearden WO, Netemeyer RG, Teel JE. Measurement of Consumer Susceptibility To Interpersonal Influence. J Consum Res 1989;15:473-481.

Bogenschneider K, Pallock L. Responsiveness in Parent-Adolescent Relationships: Are Influences Conditional? Does the Reporter Matter? J Marriage Family 2008;70:1015-1029. Bogenschneider K, Wu M, Raffaelli M, Tsay JC. Parent Influences on Adolescent Peer 
Orientation and Substance Use: The Interface of Parenting Practices and Values. Child Development 1998;69:1672-1688.

Dishion TJ, Loeber R. Adolescent Marijuana and Alcohol Use: The Role of Parents and Peers Revisited, American J Drug Alcohol Abuse 1985;11:11-25.

Duncan SC, Duncan TE, Strycker LA. Alcohol Use from Ages 9 to 16: A Cohort-Sequential Latent Growth Model. Drug and Alcohol Dependence 2006;81:71-81.

Ennett ST, Bauman KE. Mediators in the Relationship between Parental and Peer Characteristics and Beer Drinking by Early Adolescents, J Applied Social Psychology 1991;21:1699-1711.

Fletcher AC, Steinberg L, Williams-Wheeler M. Parental Influences on Adolescent Problem Behavior: Revisiting Stattin and Kerr, Child Development 2004;75:781-796.

Fuligni AJ, Eccles JS. Perceived Parent-Child Relationships And Early Adolescents' Orientation Towards Peers, Developmental Psychology 1993;29:622-632.

Hartos J, Eitel P, Simons-Morton B. Parenting Practices and Adolescent Risky Driving: A ThreeMonth Prospective Study, Health Education \& Behavior 2002;29:194-206.

Hoelter J, Harper L. Structural and Interpersonal Family Influences on Adolescent Self-Concept. J Marriage Family 1987;49:129-139.

Jackson C, Henriksen L, Dickinson D, Levine DW. The Early Use Of Alcohol And Tobacco: Its Relation To Children's Competence And Parents' Behavior, American J Public Health 1997;87:359-364.

John RD. Consumer Socialization of Children: A Retrospective Look at Twenty-Five Years of Research, J Consum Res 1999,26(December):183-213.

Kandel DB. The Parental and Peer Context of Adolescent Deviance: An Algebra Of Interpersonal Influences, J Drug Issues 1996;26:298-315. 
Kaplan HB. Self-Attitudes and Deviant Behavior: New Directions for Theory and Research, Youth \& Society 1982,14(December):185-211.

Kerr M, Stattin H, Biesecker G, Ferrer-Wreder L. Relationships with Parents and Peers in Adolescence. In Handbook of Psychology: Vol. 6. Developmental Psychology, RM Lerner, MA Easterbrooks, J Mistry (Eds.), New York: Wiley, 2003, pp. 395-419.

Lempers, JD, Clark-Lempers D, Simons RL. Economic Hardship, Distress, and Parenting in Adolescence, Child Development 1989;60:25-39.

Marsh HW. Self-description Questionnaire, SDQ Manual, The Psychological Corporation. Harcourt Brace \& Company, 1988.

Moore JN, Raymond MA, Mittelstaedt JD, Tanner JF Jr. Age and Consumer Socialization Agent Influences on Adolescents' Sexual Knowledge, Attitudes, and Behavior: Implications for Social Marketing Initiatives and Public Policy. J Public Policy Mark 2002;21(1):37-52.

Moschis GP. Consumer Socialization: A Life-Cycle Perspective 1987. Lexington, MA: Lexington Books.

Muthén LK, Muthén BO. Mplus User’s Guide, Fifth Edition, Los Angeles, CA: Muthén \& Muthén, 2007.

Openshaw DK, Thomas DL, Rollins BC. Parental Influences on Adolescent Self-Esteem, J Early Adolescence 1984;4:259-274.

Palmer TS, Pinto MB, Parente DH. College Students' Credit Card Debt And The Role Of Parental Involvement: Implications For Public Policy. J Public Policy Mark 2001,20(1):105-113.

Parish TS, McCluskey JJ. Parenting Styles, Young Adults' Self-concepts, and Evaluations of Parents, School Community Journal 1993;3(2):85-88. 
Pavlou PA, Liang H, Xue Y. Understanding and Mitigating Uncertainty in Online Exchange Relationships: A Principle-Agent Perspective. MIS Quarterly 2007,31(1):105-136.

Pavis S, Cunningham-Burley S, Amos A. Alcohol Consumption and Young People: Exploring Meaning and Social Context, Health Education Research: Theory and Practice 1997;12(3):311-322.

Pechmann C, Knight SJ. An Experimental Investigation of the Joint Effects of Advertising and Peers on Adolescents' Beliefs and Intentions about Cigarette Smoking, J Consum Res 2002;29:5-19.

Peterson GW, Hann D. Socializing Parents and Children In Families. In Handbook of Marriage and the Family, M Sussman, S Steinmetz, and GW Peterson (Eds.), New York: Plenum Press, 1999, pp. 327-370.

Podsakoff PM, MacKenzie SB, Lee J-Y, Podsakoff NP. Common Method Biases In Behavioral Research: A Critical Review of the Literature and Recommended Remedies, J Applied Psychology 2003;88(5):879-903.

Premeaux SF, Bedeian AG. Breaking the Silence: The Moderating Effects of Self-Monitoring in Predicting Speaking Up in the Workplace, Journal of Management Studies 2003;40(6):1537-1562.

Rose RL, Bearden WO, Teel JE. Attributions and Conformity in Illicit Consumption: The Mediating Role of Group Attractiveness, J Public Policy Mark 2001;20:84-92.

Shim S. Adolescent Consumer Decision-making Styles: The Consumer Socialization Perspective, Psychology and Marketing 1996;13(September):547-569.

Simons-Morton BG. Prospective Analysis of Peer and Parent Influences On Smoking Initiation among Early Adolescents, Prevention Science 2002;3:275-283. 
Stattin H, Kerr M. Parental Monitoring: A Rreinterpretation, Child Development 2000;71:10721085.

Steinberg L, Lamborn SD, Darling N, Mounts NS, Dornbusch SM. Over-time Changes In Adjustment And Competence Among Adolescents From Authoritative, Authoritarian, Indulgent, And Neglectful Families, Child Development 1994;65:754-770.

United States Congress (2009), “One Hundred Eleventh Congress of the United States of America: Division A-Family Smoking Prevention and Tobacco Control Act," (accessed August 19, 2010), [http://frwebgate.access.gpo.gov/cgi-bin/getdoc.cgi? dbname=111_cong_bills\&docid=f:h1256enr.txt.pdf].

U.S. Department of Health and Human Services 2006. A comprehensive plan for preventing and reducing underage drinking, Washington, DC: U.S. Government Printing Office. http://www.stopalcoholabuse .gov/media/underagedrinking/pdf/underagerpttocongress.pdf (accessed November 14, 2009).

Wakefield M, Terry-McElrath Y, Emery S, Saffer H, Chaloupka FJ, Szczypka G, Flay B, O’Malley PM, Johnston LD. Effect of Televised, Tobacco Company-Funded Smoking Prevention Advertising On Youth Smoking-Related Beliefs, Intentions, And Behavior. American J Public Health 2006;96:2154-2160.

Yang Z, Schaninger CM. The Impact of Parenting Strategies on Child Smoking Behavior: The Role of Child Self-Esteem Trajectory, J Public Policy Mark 2010a;29(2):232-247.

Yang Z, Schaninger CM. Parenting Strategies as Influences of Teen Drinking via Self Esteem: An Important Area for Family Policy, J Macromarketing 2010b;30(4):331-341.

Youniss JE, Smollar J. Adolescent relations with mothers, fathers, and friends. Chicago: U Chicago Press, 1985. 
FIGURE 1

A CONCEPTUAL MODEL OF PARENTING'S IMPACT ON SPI AND SUBSTANCE USE

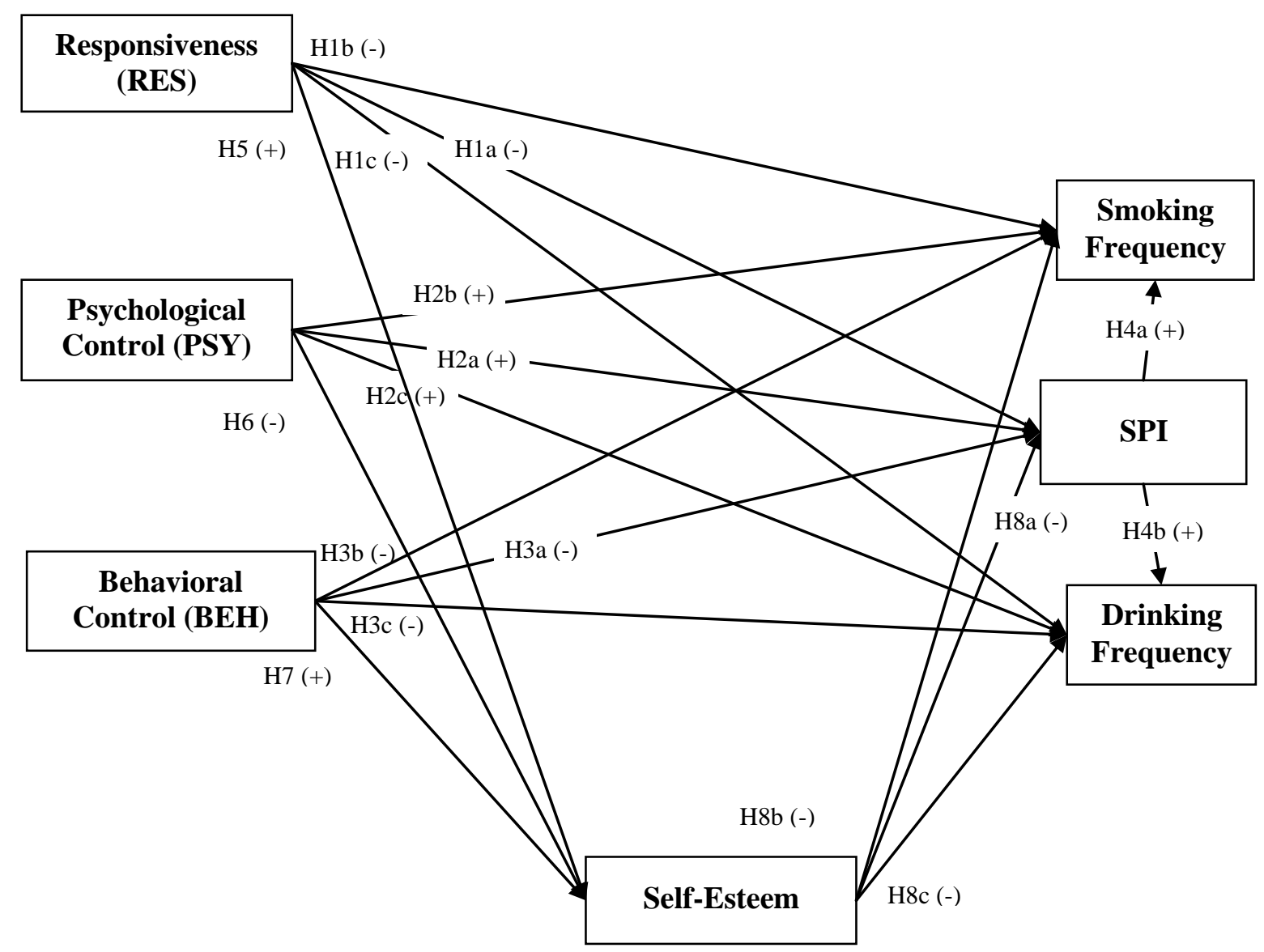

H9: Mediating role of self-esteem

H10: Timing-lagging effect of parenting strategies

Note:

SPI=Susceptibility to negative peer influence. 
FIGURE 2

THE EFFECT OF PARENTIN ON SELF-ESTEEM, SPI, AND SMOKING AND DRINKING FREQUENCIES FOR 14-15 YEAR OLDS

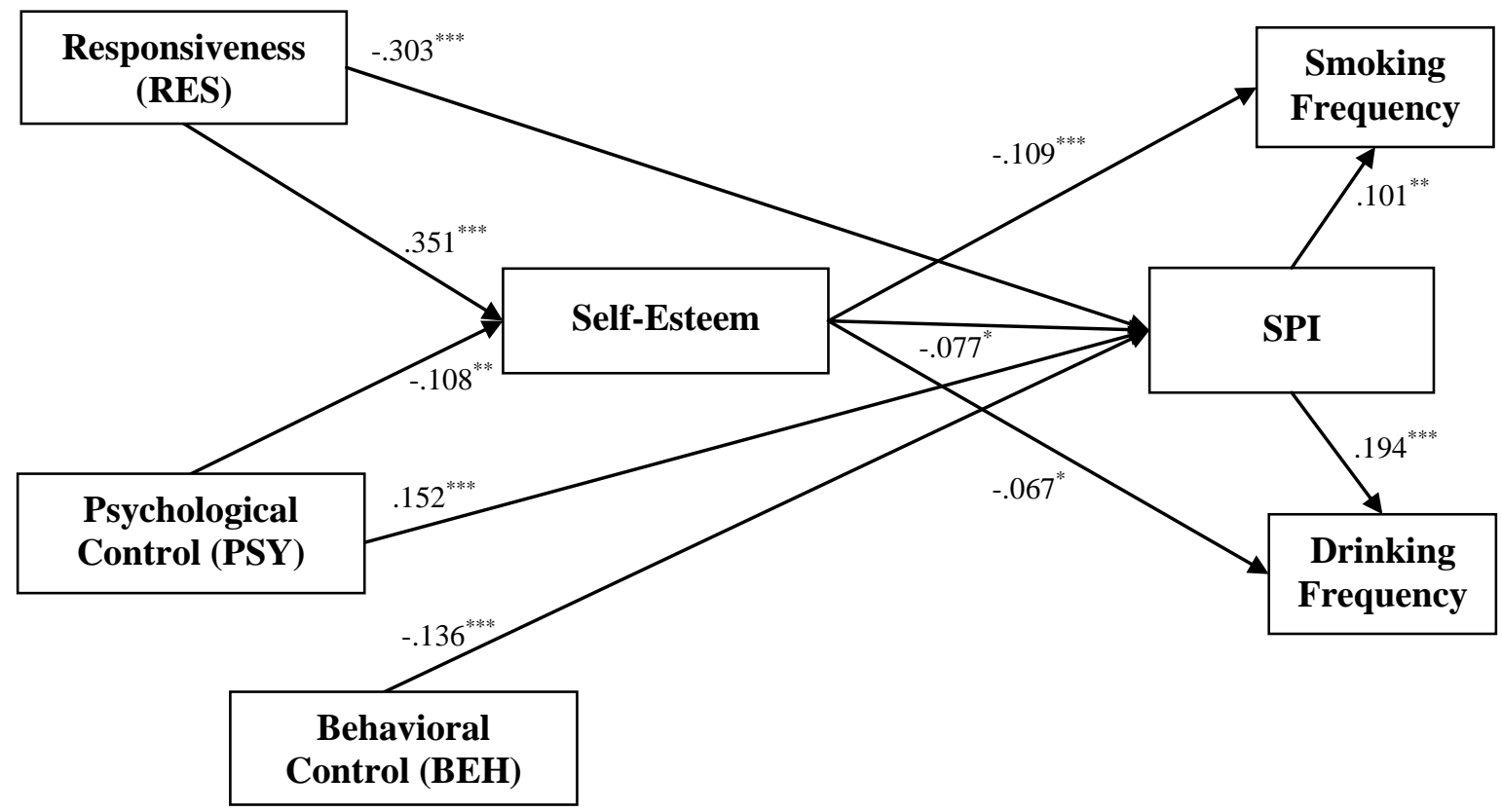

\section{Fit Indices:}

$$
\chi^{2}(\mathrm{~N}=1584)=1.4, \mathrm{df}=1, \chi^{2} / \mathrm{df}=1.4, p=.24, \mathrm{CFI}=1.00, \mathrm{RMSEA}=.000
$$

Note:

1. SPI=Susceptibility to negative peer influence.

2. There are no latent factors in the path-analysis model. The measures of parental responsiveness, psychological control, behavioral control, and self-esteem are composite scores provided by Statistics Canada. Smoking frequency, drinking frequency, and SPI are observed variables.

3. Values associated with each path are standardized regression coefficients.

4. $\quad{ }^{* * *} p<.001 ;{ }^{* *} p<.01 ;{ }^{*} p<.05$. 
FIGURE 3

LAGGED LONGITUDINAL EFFECTS OF C1 PARENTING ON C4 SELF-ESTEEM, SPI, AND SMOKING AND DRINKING FREQUENCIES

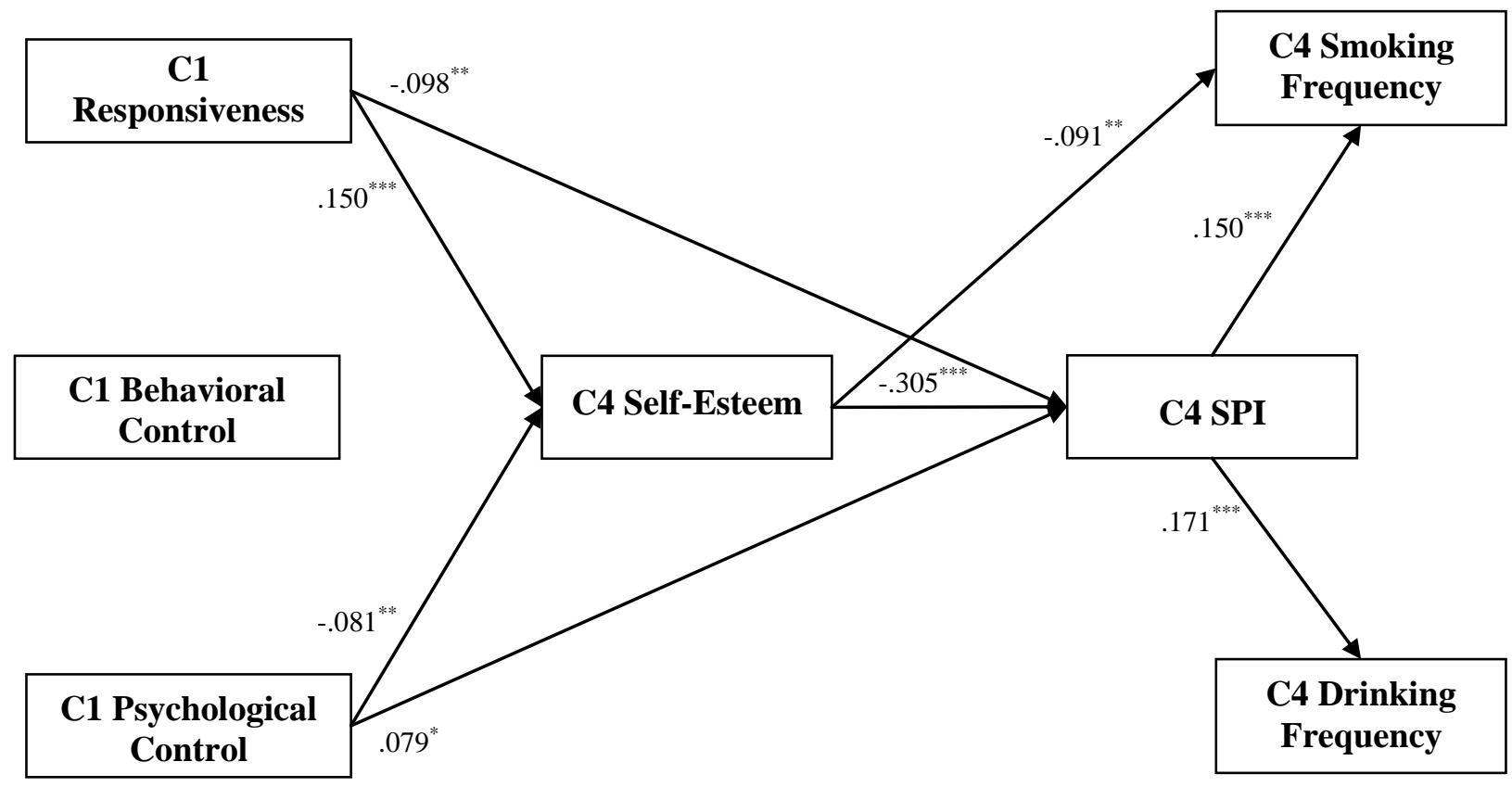

\footnotetext{
Fit Indices:

$\chi^{2}(\mathrm{~N}=1220)=0.91, \mathrm{df}=1, \chi^{2} / \mathrm{df}=0.91, p=.34, \mathrm{CFI}=1.00, \mathrm{RMSEA}=.000$
}

Note:

1. SPI=Susceptibility to negative peer influence. $\mathrm{C} 1=\mathrm{Cycle} 1$ (ages of 10-11); C4=Cycle4 (ages of 16-17).

2. There are no latent factors in the path-analysis model. The measures of parental responsiveness, psychological control, behavioral control, and self-esteem are composite scores provided by Statistics Canada. Smoking frequency, drinking frequency, and SPI are observed variables.

3. Values associated with each path are standardized regression coefficients.

4. $\quad{ }^{* * *} p<.001 ;{ }^{* *} p<.01 ;{ }^{*} p<.05$. 
TABLE 1

SUMMARY OF THE MODEL'S HYPOTHESES AND RESULTS

\begin{tabular}{|c|c|c|c|}
\hline \multirow{2}{*}{ Hypotheses } & & \multicolumn{2}{|c|}{ Results } \\
\hline & & Study 1 & Study 2 \\
\hline \multirow[t]{3}{*}{$\mathbf{H}_{\mathbf{1}}$ : Parental responsiveness is negatively related to children's: } & (a) SPI & Supported & Supported \\
\hline & (b) smoking & $\begin{array}{c}\text { Partially Supported } \\
\text { (via SPI and self-esteem) }\end{array}$ & $\begin{array}{c}\text { Partially Supported } \\
\text { (via SPI and self-esteem) }\end{array}$ \\
\hline & (c) drinking & $\begin{array}{l}\text { Partially Supported } \\
\text { (via SPI and self-esteem) }\end{array}$ & $\begin{array}{c}\text { Partially Supported } \\
\text { (via SPI and self-esteem) }\end{array}$ \\
\hline \multirow[t]{3}{*}{$\mathbf{H}_{2}$ : Parental psychological control is positively related to children's: } & (a) SPI & Supported & Supported \\
\hline & (b) smoking & $\begin{array}{c}\text { Partially Supported } \\
\text { (via SPI and self-esteem) }\end{array}$ & $\begin{array}{c}\text { Partially Supported } \\
\text { (via SPI and self-esteem) }\end{array}$ \\
\hline & (c) drinking & $\begin{array}{c}\text { Partially Supported } \\
\text { (via SPI and self-esteem) }\end{array}$ & $\begin{array}{c}\text { Partially Supported } \\
\text { (via SPI and self-esteem) }\end{array}$ \\
\hline \multirow[t]{3}{*}{$\mathbf{H}_{3}$ : Parental behavioral control is negatively related to children's: } & (a) SPI & Supported & Not Supported \\
\hline & (b) smoking & $\begin{array}{l}\text { Partially Supported } \\
\quad \text { (via SPI) }\end{array}$ & Not Supported \\
\hline & (c) drinking & $\begin{array}{l}\text { Partially Supported } \\
\text { (via SPI) }\end{array}$ & Not Supported \\
\hline \multirow[t]{2}{*}{$\mathbf{H}_{4}$ : Children's SPI is positively related to: } & (a) smoking & Supported & Supported \\
\hline & (b) drinking & Supported & Supported \\
\hline $\mathbf{H}_{5}:$ Parental responsiveness is positively related to children's self-esteem & & Supported & Supported \\
\hline $\mathbf{H}_{6}$ : Parental psychological control is negatively related to children's self-esteem & & Supported & Supported \\
\hline $\mathbf{H}_{7}:$ Parental behavioral control is positively related to children's self-esteem. & & Not Supported & Not Supported \\
\hline \multirow[t]{3}{*}{$\mathbf{H}_{\mathbf{8}}$ : Children's self-esteem is negatively related to their: } & (a) SPI & Supported & Supported \\
\hline & (b) smoking & Supported & Supported \\
\hline & (c) drinking & Supported & $\begin{array}{l}\text { Partially Supported } \\
\quad \text { (via SPI) }\end{array}$ \\
\hline $\begin{array}{l}\mathbf{H}_{9} \text { : Children's self-esteem mediates the impact of parenting strategies on SPI, } \\
\text { smoking, and drinking. }\end{array}$ & & Supported & Supported \\
\hline $\begin{array}{l}\mathbf{H}_{10} \text { : Parenting strategies in childhood have a long-lasting 'lagged,' or carryover } \\
\text { effect on subsequent SPI and substance use through self-esteem. }\end{array}$ & & Not Tested & Supported \\
\hline
\end{tabular}


